\title{
Revisão do gênero Anisocerus Lepeletier \& Audinet-Serville, 1830 (Coleoptera, Cerambycidae, Lamiinae, Anisocerini)
}

\author{
Carlos Eduardo de Alvarenga Julio ${ }^{1,2}$
}

\begin{abstract}
Revision of the genus Anisocerus Lepeletier \& Audinet-Serville, 1830 (Coleoptera, Cerambycidae, Lamiinae, Anisocerini). The genus Anisocerus and the two species, A. scopifer (Germar, 1824) and A. stellatus Guérin-Ménéville, 1855, are redescribed and illustrated. A new synonym is proposed: A. stellatus Guérin-Méneville, $1855=A$. onca White, 1855 syn. nov. The two species are redescribed and illustrated.
\end{abstract}

Keywords. Anisocerini; Anisocerus; Cerambycidae; Neotropical; taxonomy

\section{INTRODUÇÃO}

LACORDAIRE (1830: 170;181) destacou no início de suas notas sobre Cerambycidae que utilizou, para os gêneros, os nomes criados por Lepeletier \& Audinet-Serville, já que o trabalho destes ainda era inédito: "Je suivrai pour le genres, les coupes nombreuses creés par MM. Lepeletier de SaintFargeau et A. Serville, que se sont spécialment occupés de ces Insectes; et, comme leur travail est encore inédit, je rapporterai tous ces genres à ceux du Catalogue de M. le comte Dejean, lorsque cela sera possible". Descreveu Anisocerus penicillatus ao comentar o aspecto de suas antenas "Anisocerus (Lepel. et Serv.), Acanthocinus (Fab.). A. penicillatus, remarquable par les faisceaux de poils de ses antennes, particularité trés-rare chez les Acanthocinus. Cette espèce n'est pas commune." - disponibilizando, desta maneira, o gênero Anisocerus Lepeletier \& Audinet-Serville in Lacordaire, 1830.

Audinet-Serville (1835:79) descreveu Anisocerus e relacionou apenas uma espécie, $A$. scopifer (Germar, 1824), à qual sinonimizou A. penicillatus Lacordaire, 1830.

Guérin-MénevilLe (1855:599) listou duas espécies em Anisocerus, A. scopifer e A. stellatus, que descreveu do Peru, e White (1855:405) listou dez espécies, entre elas, A. scopifer; A. capucinus (White, 1846), transferida de Compsosoma; $A$. decorator (Fabricius, 1801), transferida de Lamia e, posteriormente, transferida para Xilotribus Audinet-Serville, 1835 por LaCoRDAire (1872:724); e descreveu A. onca, $A$. dulcissimus, A. monachinus e A. egensis, todas do Amazonas
(Brasil) e A. leucophaeus e A. palliatus da Guatemala.

Bates $(1862: 447 ; 449)$ transferiu A. egensis para Chalastinus; comentou que desde que Anisocerus foi erigido, espécies que considerava não pertencer ao gênero foram descritas nele e, em decorrência deste fato, redescreveu Anisocerus arrolando uma série de caracteres que restringiram o número de espécies no gênero. Descreveu duas variedades para $A$. onca, $A$. onca var. fonteboensis e $A$. onca var. olivencius, e comentou: "I have no doubt, on perusing the excellent description, that the A. stellatus of Guérin-Ménéville, found in Ecuador, probably on the banks of the Napo, is a further modification of the $A$. onca, in the direction of our var. olivencius" (BATES, l. c., p. 450). Transferiu, ainda, A. capucinus, A. dulcissimus e $A$. monachinus para Gymnocerus Audinet-Serville, 1835. A. capucinus e A. dulcissimus foram transferidas, mais tarde, por LANE (1964:195) e LANE (1970:378), respectivamente, para Gounellea Lane, 1964 e LANE (1964:194) erigiu Jurua para A. monachinus. Bates (1869:385) descreveu Anisocerus personatus e sinonimizou-a com A. palliatus (BATEs 1872:203). LACORDAire (1872:722) transferiu A. leucophaeus para Gymnocerus, posteriormente transferida para Thryallis Thomson, 1858 por Bates (1880). Martins \& Galileo (1996:305) transferiram A. palliatus para Phacellocera Laporte, 1840 e posteriormente GaliLEO \& MARTins (1998:22) transferiram-na para Caciomorpha Thomson, 1864.

O estudo de exemplares pertencentes à coleção do Museu Nacional, Universidade Federal do Rio de Janeiro, Rio de Janeiro (MNRJ) e dos diapositivos dos tipos feitos por J. S. Moure do Departamento de Zoologia, Universidade Federal

\footnotetext{
1. Departamento de Entomologia, Museu Nacional, Universidade Federal do Rio Janeiro. Quinta da Boa Vista, São Cristóvão, 20940-040 Rio de Janeiro-RJ, Brasil. Endereço eletrônico: ceajulio@ig.com.br

2. Doutorando em Ciências Biológicas, Área de Concentração Zoologia, Instituto de Biociências, UNESP/Botucatu.
} 
do Paraná, Curitiba (DZUP), no Muséum National d'Histoire Naturelle, Paris (MNHN) e The Natural History Museum, Londres (BMNH), permitiu propor a sinonímia entre A. stellatus e $A$. onca e redescrever o gênero e suas espécies.

As referências bibliográficas sob cada táxon referem-se à descrição original e ao catálogo de MonNÉ (1994).

\section{Anisocerus Lepeletier \& Audinet-Serville, 1830}

Anisocerus Lepeletier \& Audinet-Serville in Lacordaire, 1830:181; Monné, 1994:10 (cat.).

Anisaerus [sic]; Drapiez, 1837:221.

Espécie-tipo: Anisocerus penicillatus Lacordaire, 1830 (monotipia) $=$ Lamia scopifera Germar, 1824.

Fronte ligeiramente convexa, granulada no centro, com os lados um pouco divergentes para a região inferior e borda inferior reta nas fêmeas e reta ou bissinuosa nos machos. Olhos grandes não-divididos, com várias fileiras de omatídios unindo os lobos superior e inferior; lobos oculares superiores tão distantes entre si quanto a maior largura de um lobo. Tubérculos anteníferos separados entre si, mais ou menos projetados, com pequena escavação entre eles, mais acentuada nos machos. Antenas mais longas que o corpo, com onze artículos nos machos e dez nas fêmeas; escapo clavado, nas fêmeas adelgaçado na base; antenômero III com denso tufo de pêlos no lado interno do ápice, com comprimento, aproximado, dos dois ou três seguintes reunidos; demais antenômeros gradualmente decrescentes em comprimento; XI, nos machos, com metade do comprimento do X.

Protórax mais largo que longo, com tubérculo lateral cônico bastante desenvolvido; pronoto com dois tubérculos láteroanteriores proeminentes e calo centro-basal manifesto; as margens anterior e posterior com uma fileira de pontos profundos. Processo mesosternal bituberculado e escavado no centro. Élitros planos no dorso, com os lados subparalelos; disco com gibosidade centro-basal, granulada, desenvolvida ou não; úmeros granulados e protuberantes; ápices arredondados ou subarredondados. Tíbias sub-retas, com pequena dilatação no ápice; protarsos franjados nos machos.

Urosternito $\mathrm{V}$, nas fêmeas, tão longo quanto os três anteriores reunidos, levemente intumescido no ápice e com pequeno sulco no centro da metade basal.

Comentários. Assemelha-se a Caciomorpha Thomson, 1864 pelos olhos não-divididos, com várias fileiras de omatídios unindo os lobos superior e inferior; pelas antenas mais longas que o corpo; pelo aspecto do antenômero III, mais longo que os demais e com intumescimento provido de pêlos no lado interno do ápice; pela presença no protórax de um tubérculo lateral; pelo pronoto trituberculado; pela presença nos élitros de gibosidade centro-basal e pelas tíbias sub-retas, com pequena dilatação no ápice. Distingue-se de Caciomorpha pelos tubérculos anteníferos afastados entre si; pelo escapo clavado; pelo aspecto do tubérculo lateral do protórax, cônico e bastante desenvolvido; pelo aspecto mais robusto e protuberante dos tubérculos do pronoto; pelo processo mesosternal bituberculado, com escavação central; pelo formato dos élitros, apenas um pouco mais longos que largos e pelo urosternito $\mathrm{V}$ das fêmeas levemente intumescido no ápice. Em Caciomorpha: os tubérculos anteníferos são próximos entre si; o escapo é piriforme, com o lado dorsal da base plano ou ligeiramente aprofundado; o tubérculo lateral do protórax é pouco projetado e com um pequeno espinho no topo; tubérculos do pronoto apenas manifestos, pouco desenvolvidos; processo mesosternal plano, sem tubérculos; élitros bem mais longos que largos; urosternito $\mathrm{V}$, nas fêmeas, com depressão semicircular centro-apical.

\section{Anisocerus scopifer (Germar, 1824)}

(Fig. 1)

Lamia scopifera Germar, 1824: 476.

Acanthocinus scopifer; Perty, 1832: 95, pl. 19, fig.6.

Anisocerus scopifer; Audinet-Serville, 1835: 79; Monné, 1994: 10 (cat.). Anisocerus scopigera [sic]; Lacordaire, 1872: 723.

Anisocerus penicillatus Lacordaire, 1830: 181; Audinet-Serville, 1835: 79 (sin.).

Macho. Tegumento castanho-escuro; cabeça, antenômeros I-III, protórax, pernas e superfície ventral do corpo recobertos por pubescência esbranquiçada.

Fronte com grânulos concentrados na região central, os lados um pouco divergentes inferiormente e borda inferior reta; sutura epistomal levemente bissinuosa. Região entre os lobos oculares superiores com duas faixas longitudinais negras. Tubérculos anteníferos pouco projetados. Antenas com onze artículos, ultrapassam os ápices elitrais a partir do antenômero IV; escapo clavado; antenômero III tão longo quanto os três seguintes reunidos, provido com um denso tufo de pêlos negros no lado interno do ápice; IV-X castanhoclaros, com o ápice castanho-escuro e um pequeno tufo de pêlos esparsos no lado interno, com exceção do $\mathrm{X}$ onde os pêlos estão distribuídos ao redor do ápice; o XI é afilado para o ápice.

Tubérculo lateral do protórax cônico, bastante desenvolvido; pronoto com uma faixa longitudinal central negra desde a margem anterior até a posterior, recobrindo os tubérculos anteriores e o calo central; tubérculos láteroanteriores cônicos, proeminentes; calo centro-basal estriado e um pouco elevado; margens anterior e posterior profundamente pontuadas. Escutelo com uma mácula negra ocupando a maior parte da superfície. Élitros com uma faixa transversal mediana branca de contornos irregulares salpicada por pequenas máculas negras esparsas e margeada posteriormente por uma linha em zigue-zague negra; terço basal granulado, revestido por pubescência ocre e com grandes máculas negras irregulares, algumas concentradas abaixo das gibosidades centro-basais e dos úmeros e outras próximas à sutura; terço apical recoberto por pubescências ocre e branca, esta nos ápices; gibosidades centro-basais protuberantes; ápices subarredondados. Tíbias e tarsômeros $\mathrm{V}$ com ápice negro. 
Fêmea. Região entre os tubérculos anteníferos com escavação rasa. Antenas com dez artículos, ultrapassam os ápices elitrais em apenas três antenômeros; escapo adelgaçado na base; antenômeros IV-X sem tufo de pêlos.

Dimensões $(\mathrm{mm})$, respectivamente macho/fêmea. Comprimento total, 8,0-16,0/10,6-17,6; comprimento do protórax, 1,5-3,2/2,0-3,5; maior largura do protórax, 3,4-7,3/ 4,6-7,6; comprimento do élitro, 5,7-11,3/7,9-12,5; largura umeral, 4,0-8,0/5,5-9,0.

Material examinado. BRASIL. Espírito Santo: Barra de São Francisco (Córrego do Itá), 19 machos e 7 fêmeas, XI/1954, W. Grossmann col., macho, I/1955, W. Grossmann col., 2 machos e 2 fêmeas, I/1955, W. Zikán col., fêmea, XI/1956, W. Grossmann col., fêmea, XI/1956 W. Zikán col., macho, II/1957, José H. Guimarães col.; Linhares, macho, III/1954, P.A. Teles col., macho e fêmea, XII/ 1964, fêmea, I/1965, Sérgio A. Fragoso col., 2 machos e fêmea, XI/ 1967, F.M.Oliveira col., macho, XII/1967, macho, I/1968, fêmea, I/ 1969, macho, I/1970, macho e fêmea, I/1971, M. Morais col.; (Parque Sooretama), fêmea, III/1953, Pedro Almeida Teles col., 2 fêmeas, XI/ 1964, F. Oliveira, Werner \& C.A. Seabra cols., 18 machos e 18 fêmeas, X/1967, F.M.Oliveira col., 18 machos e 10 fêmeas, XI/1967, F.M. Oliveira col.; Tijuco Preto, macho e fêmea, XI/1937, macho e fêmea, 1940. Rio de Janeiro: Rio de Janeiro (Corcovado), fêmea, XII/1932, L. Travassos col., macho, X/1953, fêmea, XI/1955, fêmea, XI/1956, macho, XII/1956, fêmea, X/1957, D. Zajciw col., fêmea, X/1957, Seabra \& Alvarenga cols., macho, XI/1957, D. Zajciw col., 2 machos, XII/1957, D. Zajciw col., macho, XII/1957, Seabra col., macho e 3 fêmeas, I/1958, Seabra col., macho e 2 fêmeas, III/1958, Seabra col., macho, X/1958, D. Zajciw col., fêmea, X/1958, Alvarenga \& Seabra cols., macho e 4 fêmeas, XII/1958, D. Zajciw col., macho, VI/1959, fêmea, VIII/1959, macho e fêmea, X/1959, macho, III/1960, Alvarenga \& Seabra cols., macho e fêmea, XI/1960, Seabra col., macho, III/1961, Alvarenga \& Seabra cols., macho, IX/1961, Alvarenga \& Seabra cols., macho, X/1966, S.A. Fragoso col., macho e 2 fêmeas, VIII/1967, macho, IX/1967, 2 machos e 4 fêmeas, X/1967, Alvarenga \& Seabra cols., fêmea, X/1967, Fragoso col., 2 machos e 2 fêmeas, XI/1967, macho IX/1969, macho e 6 fêmeas, XI/1969, Alvarenga \& Seabra cols., fêmea, IX/1975, Monné col., 10 machos e 9 fêmeas, X/1975, macho e fêmea, XI/1975, macho e 2 fêmeas, X/1976; fêmea, IX/1979, Monné \& Seabra cols., fêmea, I/1980, Seabra col.; (Floresta da Tijuca), macho, II/1939, fêmea, IV/1953, 7 machos e 6 fêmeas, XII/1956, macho e fêmea, I/ 1961, macho, III/1966, fêmea, V/1968, 2 machos e fêmea, I/1969, macho, I/1970, fêmea, I/1974, fêmea, II/1976, macho, III/1976, fêmea, V/1981, C.A. Campos Seabra col.; (Itatiaia), fêmea, IX/1935, Zikán col., fêmea, II/1955, H. Gouvea col.; (Represa Rio Grande), macho, X/ 1960, F.M. Oliveira col. São Paulo: São Paulo, fêmea; Cantareira, fêmea, XII/1953, H. Zellibor col.; Indiana, macho, X/1934, macho, XI/1934, Zellibor-Hauff col., macho, XI/1935, Zellibor-Hauff col.; Marília, macho, XI/1945, H. Zellibor col.; Teodoro Sampaio, fêmea, XI/1973, F.M. Oliveira col. Paraná: Matelândia, macho e fêmea, XI/ 1961; Rolândia, macho, II/1954; Rondon, 2 machos e fêmea, X/1952, Fritz Plaumann col. Santa Catarina: Corupá, macho, XI/1960, fêmea, XI/1961; Seara (Nova Teutônia), fêmea, XI/1940, 2 fêmeas, XI/1941, fêmea, XII/1941, macho, XI/1942, macho e fêmea, XII/1942, Fritz Plaumann col. (MNRJ).

\section{Anisocerus stellatus Guérin-Méneville, 1855} (Fig. 2)

Anisocerus stellatus Guérin-Méneville, 1855: 599; Monné, 1994: 11 (cat.).

Anisocerus onca White, 1855: 405, pl. 10, fig. 4; Monné, 1994: 10 (cat.). Syn. nov.

Anisocerus onca var. fonteboensis Bates, 1862: 449; Monné, 1994: 10 (sin. de Anisocerus onca).
Anisocerus onca var. olivencius Bates, 1862: 450; Monné, 1994: 10 (sin. de Anisocerus onca).

Macho. Tegumento predominantemente castanhoavermelhado. Pubescência castanho-clara reveste as pernas e a superfície ventral do corpo e parcialmente a cabeça, o pronoto e os élitros.

Fronte com densa granulação central e borda inferior levemente bissinuosa; sutura epistomal reta. Tubérculos anteníferos projetados. Antenas com onze artículos, ultrapassam os ápices elitrais a partir do meio do antenômero V; escapo clavado, negro; antenômero III com um denso tufo de pêlos negros no lado interno do ápice, tão longo quanto IV + a metade do V; antenômeros IV-X com o ápice negro e sem tufo de pêlos; o XI curvo.

Lados do protórax com duas faixas negras longitudinais, uma sobre o tubérculo e outra mais abaixo; tubérculo lateral cônico e desenvolvido. Pronoto com os tubérculos láteroanteriores e calo centro-basal pouco elevados e com uma grande mácula negra sobre e abaixo de cada um; calo centrobasal estriado. Élitros com o quarto basal densamente granulado; superfície do disco recoberta por máculas negras, arredondadas e retangulares, assim distribuídas: cinco ao redor da gibosidade centro-basal, sendo quatro arredondadas e uma retangular, alongada, próxima à sutura; seis na região central, três arredondadas próximas à margem lateral e três retangulares mais internas, sendo uma próxima à sutura; e quatro menores, retangulares, na região apical. Gibosidades elitrais centrobasais discretas; ápices arredondados. Metade apical ventral dos fêmures e ápice das tíbias, negros; tarsômeros amarelados.

Fêmea. Região entre os tubérculos anteníferos com escavação rasa. Antenas com dez artículos, ultrapassam os ápices elitrais em apenas três antenômeros; escapo adelgaçado na base; antenômeros IV-X gradualmente decrescentes em comprimento.

Dimensões $(\mathrm{mm})$, respectivamente macho/fêmea. Comprimento total, 8,5-15,5/10,5-15,3; comprimento do protórax, 1,7-3,4/1,9-2,7; maior largura do protórax, 3,5-6,4/ 4,0-6,1; comprimento do élitro, 5,9-11,1/7,7-11,3; largura umeral, 4,4-8,0/5,1-7,5.

Comentários. Como variações cromáticas A. stellatus apresenta, nos exemplares do Brasil (Amazonas) e Equador, os élitros parcialmente revestidos por pubescência castanhoescura e máculas brancas esparsas entre, ou substituindo, as máculas negras centrais e apicais.

Assemelha-se a $A$. scopifer (Germar, 1824) pela fronte granulada na região central; pelos olhos não-divididos; pelos tubérculos anteníferos separados entre si; pelo aspecto do antenômero III, com um denso tufo de pêlos no lado interno do ápice e pelo processo mesosternal bituberculado. Distinguese de $A$. scopifer pela borda inferior da fronte bissinuosa nos machos; pelo comprimento das antenas dos machos que ultrapassam os ápices elitrais a partir do meio do antenômero $\mathrm{V}$; pelo comprimento do antenômero III, tão longo quanto IV + a metade do V; pelos antenômeros IV-X desprovidos de tufo 

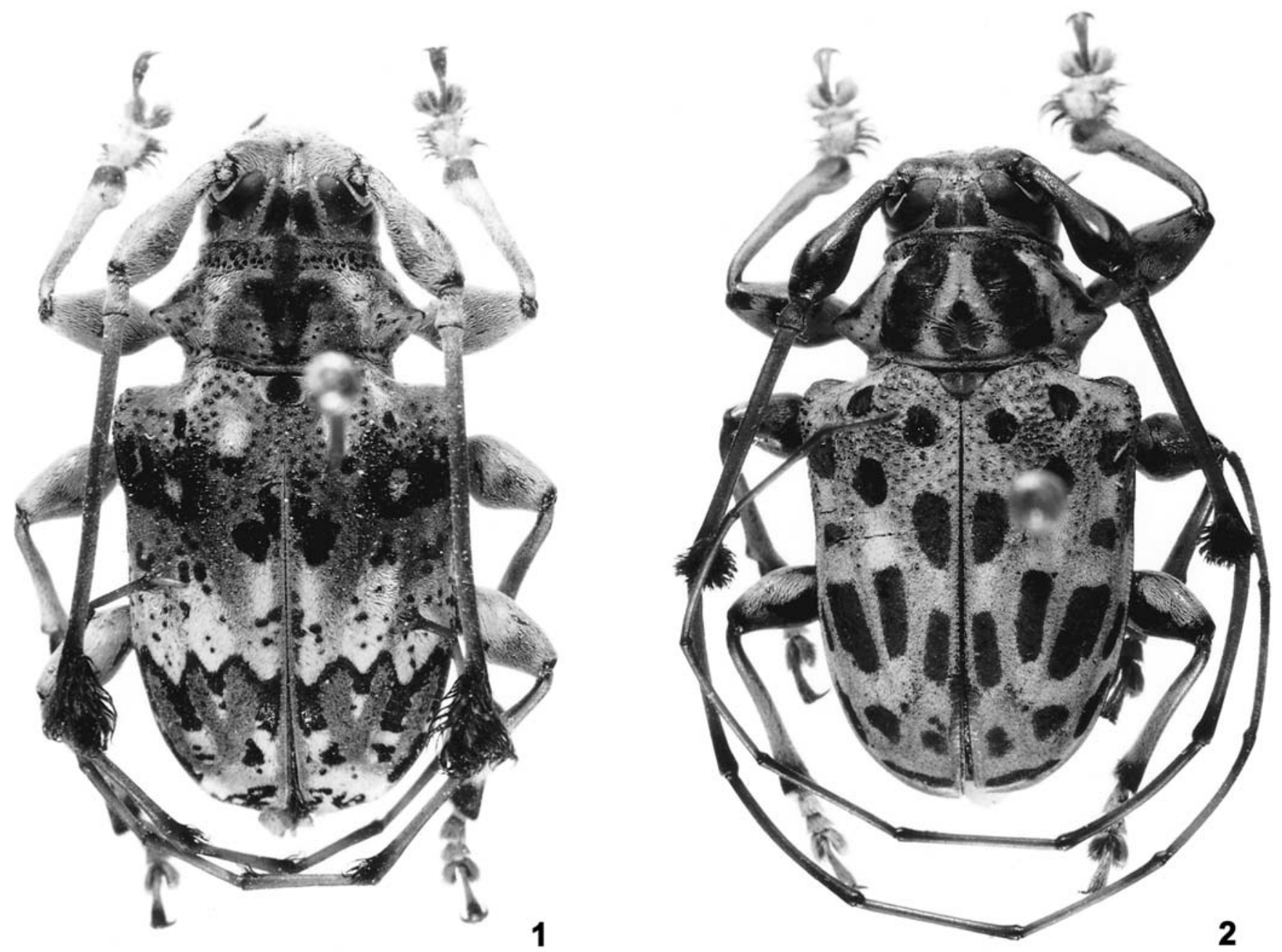

Figs. 1-2. 1, Anisocerus scopifer (Germar, 1824), macho, Rio de Janeiro (Corcovado), Brasil, comprimento 14,2 mm. 2, Anisocerus stellatus GuérinMéneville, 1855, macho, Ouro Preto do Oeste, Rondônia, Brasil, comprimento, 12,8 mm.

de pêlos; pelos tubérculos látero-anteriores do pronoto discretos, pouco elevados; pelo padrão de coloração dos élitros, recobertos por máculas negras, arredondadas e retangulares; pelas gibosidades centro-basais dos élitros discretas e pelos ápices arredondados. Em A. scopifer: a borda inferior da fronte, nos machos, é reta; as antenas dos machos ultrapassam os ápices elitrais a partir do antenômero IV; o antenômero III é tão longo quanto os três seguintes reunidos; antenômeros IV-IX com um pequeno tufo de pêlos esparsos no lado interno e o X com os pêlos distribuídos ao redor do ápice; tubérculos látero-anteriores do pronoto, cônicos e proeminentes; os élitros apresentam uma faixa transversal mediana branca de contornos irregulares salpicada por pequenas máculas negras, esparsas e margeada, posteriormente, por uma linha em zigue-zague negra, o terço basal é revestido por pubescência ocre com grandes máculas negras irregulares, algumas concentradas abaixo das gibosidades centro-basais e dos úmeros e outras próximas à sutura, e o terço apical é recoberto por pubescências ocre e branca, esta nos ápices; gibosidades centro-basais protuberantes e ápices subarredondados.
Material examinado. BOLÍVIA. Santa Cruz, fêmea. PERU, Huanuco: Tingo Maria, 3 machos, IV/1965. Junin: Chanchamayo, 2 machos e 2 fêmeas, XI/1949, macho, I/1950, H. Zellibor col.; Satipo, 2 machos e fêmea, 3 machos e 4 fêmeas, Papryzscki col, 2 machos e fêmea, VII/1937, fêmea, IX/1937, 2 machos e fêmea, X/1937, macho e fêmea, IV/1938, 2 machos e 2 fêmeas, 1940, macho, VIII/1941, fêmea, II/1942, fêmea, III/1942, 3 machos, IV/1942, Papryzscki col., macho, XI/1942, fêmea, IV/1943, macho, VI/1943, macho e fêmea, VII/1943, macho, IX/1948, fêmea, II/1959, 2 machos e fêmea, III/ 1959. Loreto: Aucayacu, 2 machos e 2 fêmeas, IX/1966, M. Dourojeanni col.; Pucallpa, 7 machos e 2 fêmeas, IX/1950, macho e fêmea, XII/ 1950, macho e fêmea, II/1952, H. Zellibor col., macho e fêmea, XII/ 1962, macho e 2 fêmeas, XI/1968, J. Schunke col., macho, IX/1970, 7 machos e 3 fêmeas, X/1970, 13 machos e 15 fêmeas, XI/1970, macho e fêmea, XII/1970, macho e fêmea, I/1971, J. Schunke col., macho, X/ 1978, fêmea, I/1980, J. Becker col. Madre de Dios: Avispas, 2 machos e fêmea, IX/1962, L. Peña col. EQUADOR. Napo: Lago Agrio, macho e 5 fêmeas, XI/1977, J. Escobar col.. Oriente: Tena, fêmea, II/1957, L. Peña col. BRASIL. Amazonas: Atalaia do Norte, fêmea, XI/1977, B. Silva col.; Benjamin Constant, 7 machos e 5 fêmeas, II/1942, 3 machos e 2 fêmeas, IV/1942, 4 machos e 2 fêmeas, 1943, A. Parko col., 2 machos e fêmea, IX/1955, 4 machos, VI/1956, I.C. Lima col.; (Rio Javari), 12 machos e 9 fêmeas, III/1942, macho, IX/1942, A. Parko col.; (Rio Quichito), fêmea, X/1942, 9 machos e 3 fêmeas, XII/1942, A. Parko col.; Borba (Guajará), 2 machos, VII/1943, A. Parko col.; (Lago Acará), macho e fêmea, XI/1943, A. Parko col.; Fonte Boa, 
fêmea, IX/1975, L. Otero col., 3 machos e fêmea, X/1975, F.M. Oliveira col.; Manaus, 2 machos, X/1961, M. Melo col.; Tabatinga, macho e fêmea, IV/1957, 2 machos, IV/1959, F.M. Oliveira col., 2 machos e 2 fêmeas, XII/1977, B. Silva col., 4 machos e 2 fêmeas, VIII/1978, B. Silva col.; Tefé, 4 machos e 2 fêmeas, I/1962, R. Carvalho col. Pará: Óbidos, fêmea, IV/1959, F.M. Oliveira col. Rondônia: Ariquemes, macho, VIII/1979, B. Silva col., macho e 2 fêmeas, VIII/1980, B. Silva col.; macho, XI/1991, Bezark col.; Ouro Preto do Oeste, 2 machos e 3 fêmeas, X/1983, macho, XI/1983, O. Roppa, J. Becker \& B. Silva cols, 5 machos e 4 fêmeas, X/1986, O. Roppa, P. Magno \& J. Becker cols; Pimenta Bueno, fêmea, XI/1960, M. Alvarenga col.; Porto Velho (Cachoeira do Samuel), 4 machos e 3 fêmeas, VIII/1944, A. Parko col.; (Foz do Rio Madeira), fêmea, XII/1943, A. Parko col.; Vilhena, macho, XI/1973, Alvarenga \& Roppa cols. Mato Grosso: Barra do Bugres, macho e fêmea, X/1984, O. Roppa e B. Silva cols. (MNRJ).

Agradecimentos. Ao Dr. Miguel A. Monné (MNRJ) pelas sugestões e revisão do manuscrito; ao Dr. Renato C. Marinoni (DZUP) pelo empréstimo dos diapositivos; a Sérgio Barbosa Gonçalves pela execução das fotografias e à Fundação de Amparo à Pesquisa do Estado de São Paulo (FAPESP, Proc. $\mathrm{n}^{\circ}$ 98/10692-5) pela bolsa de Doutorado concedida.

\section{REFERÊNCIAS}

Audinet-Serville, J. G. 1835. Nouvelle classification de la famille des longicornes. Annales de la Société Entomologique de France 4(1): 5-100.

Bates, H.W. 1862. Contributions to an insect fauna of the Amazon Valley. Coleoptera. Longicornes. Annals and Magazine of Natural History 9(3): 446-458.

Bates, H. W. 1869. New species of Coleoptera from Chontales, Nicaragua. Transactions of the Entomological Society of London 1869: 383-389.

Bates, H. W. 1872. On the longicorn Coleoptera of Chontales, Nicaragua. Transactions of the Entomological Society of London 1872: $163-238$
Bates, H. W. 1880. Biologia Centrali-Americana, Insecta, Coleoptera, 5: $17-152$

Drapiez, M. 1837. Dictionnaire classique des Sciences Naturelles. Bruxelles, Meline, Cans et Co., vol. 1, 640 p.

Galile, M .H. M. \& U. R. Martins. 1998. Divisão do gênero Phacellocera (Coleoptera, Cerambycidae, Lamiinae, Anisocerini). Iheringia, Série Zoologia (85): 11-25.

Germar, E. F. 1824. Insectorum species novae aut minus cognitae, descripitionibus illustratae. Halae, Hendel \& Sons, xxiv +624 p., 2 pls.

GuéRIN-MénÉviLle, F. E. 1855. Catalogue des insectes recueilles par M. Gaetano Osculati, pendant son exploration équatoriale, sur les bords du Napo et 1'Amazone. Verhandlungen der zoologischbotanischen Gesellschaft in Wien 5: 573-612.

LACORDAiRE, J. T. 1830. Mémoire sur les habitudes des insectes coléoptères de l'Amérique méridionale. Annales des Sciences Naturelles 21: 149-194.

Lacordaire, J. T. 1872. Histoire Naturelle des Insectes. Genera des Coléoptères. Paris, Roret, 9(2): 411-930.

Lane, F. 1964. Novos gêneros e espécies de Anisocerini (Coleoptera, Lamiidae). Studia Entomologica 7: 179-200.

LANE, F. 1970. Cerambycoidea Neotropica nova VII (Coleoptera). Studia Entomologica 13 (1-4): 369-428.

Lepeletier, A. L. M. \& J. G. Audinet-Serville. 1830. In: J. T. Lacordaire, Mémoire sur les habitudes des insectes coléoptères de l'Amérique méridionale. Annales des Sciences Naturelles 21: 149-194.

Martins, U. R. \& M. H. M. Galileo. 1996. Descrições e notas sobre Cerambycidae (Coleoptera) Sul-Americanos. Revista Brasileira de Zoologia 13(2): 291-311.

Monné, M. A. 1994. Catalogue of the Cerambycidae (Coleoptera) of the Western Hemisphere. Part XVII. São Paulo, Sociedade Brasileira de Entomologia, 110 p.

Perty, J. A. M. 1832. Delectus animalium articulatorum quae in itinere per Brasilian annis MDCCCXVII-MDCCCXX jussu at auspicis Maximiliani Josephi I. Bavariae regis augustissime peracto collegerunt Dr. J.B. de Spix et Dr. C.F. Ph. de Martius. Monachii, 61-124, pls. 13-24.

White, A. 1855. Catalogue of the coleopterous insects in the collection of the British Museum. Longicornia 2. London, 8: 175-412, pls. $5-10$ 